\title{
Acta Iguazu
}

ISSN: 2316-4093

\section{Caracterização morfométrica, climática e de uso do solo da Bacia hidrográfica do rio Farinha-MA}

Nathália Coelho Nobre ${ }^{1, *}$, Cristiane Matos da Silva ${ }^{2}$, Jhonata Santos Santana ${ }^{3}$, Wilson Araújo da Silva ${ }^{4}$

1 Graduada em Engenharia Florestal-Universidade Estadual do Maranhão-UEMA Imperatriz, Maranhão, Brasil.

2 Mestranda em Engenharia de Barragem e Gestão Ambiental - UFPA - Campus de Tucuruí.

3 Bolsista de Apoio Técnico Institucional na Universidade Estadual da Região Tocantina do MaranhãoUEMASUL

${ }^{4}$ Professor Adjunto III do curso de Engenharia Agronômica do Centro de Ciências Agrárias da UEMASUL CAMPUS IMPERATRIZ Imperatriz, Maranhão, Brasil.

\footnotetext{
*Autor correspondente: nathaliaacn@gmail.com Artigo enviado em 09/03/2018, aceito em 13/12/2019
}

Resumo: A caracterização morfométrica é fundamental para os estudos hidrológicos, pois possui estreita relação com o comportamento hidrológico da bacia. 0 objetivo deste trabalho foi determinar as características morfométricas, e avaliar as condições climáticas e de uso do solo da bacia hidrográfica do rio Farinha, localizada no sudoeste do estado do Maranhão. O trabalho foi desenvolvido utilizando o SIG, ArcMap 10.1, escolhendo-se doze parâmetros, determinados com base em cartas topográficas, na escala de 1:100.000, obtidas junto a Diretoria de Serviço Geográfico do Exército Brasileiro e através dos dados SRTM. A caracterização climática foi realizada com base em registros mensais de 4 estações meteorológicas localizadas em cidades no entorno da bacia. Na caracterização de uso e ocupação do solo da bacia, foram utilizados dados do projeto TerraClass. A área de drenagem foi de $5255,79 \mathrm{~km}^{2}$ e o perímetro $398,43 \mathrm{~km}$. 0 fator de forma foi de 0,35, o coeficiente de compacidade de 1,54 e o índice de circularidade de 0,42 , remetendo a uma bacia de formato alongado. A bacia possui declividade média de $4^{\circ}$ e altitude média de $346 \mathrm{~m}$. A densidade hidrográfica foi de 0,07 canais. $\mathrm{km}^{-2}$ e a densidade de drenagem foi de $0,42 \mathrm{~km} \cdot \mathrm{km}^{-2}$. A precipitação anual dentro da bacia variou de 1369 a $1721 \mathrm{~mm}$ e a temperatura média compensada de 27,0 a $27,3^{\circ} \mathrm{C}$. $\mathrm{O}$ uso do solo predominante é a forma natural, representando $76,93 \%$ da extensão da bacia.

Palavras-chave: comportamento hidrológico, densidade de drenagem, SIG.

\section{Morphometric, climatic and land use characterization of watershed of the Farinha-MA river}

Abstract: The morphometric characterization is fundamental for the hydrological studies, since it has a close relation with the hydrological behavior of the basin. The objective of this work was to determine the morphometric characteristics and to evaluate the climatic and land use conditions of the Farinha river basin, located in the southwest of the State of Maranhão. The work was developed using the SIG, ArcMap 10.1, choosing twelve parameters, determined based on topographic charts, in the scale of 1: 100,000, obtained from the Geographic Service Directorate of the Brazilian Army and through SRTM data. The climatic characterization was performed based on monthly records of 4 meteorological stations located in cities around the basin. In the 
characterization of land use and occupation of the basin, data from the TerraClass project were used. The drainage area was $5255.79 \mathrm{~km}^{2}$ and the perimeter was $398.43 \mathrm{~m}$. The shape factor was 0.35 , the compactness coefficient was 1.54 and the circularity index was 0.42 , referring to an elongated shaped basin. The basin has an average slope of $4^{\mathrm{o}}$ and an average elevation of 346 meters. The hydrographic density was 0.07 channels. $\mathrm{km}^{-2}$ and the drainage density was $0.42 \mathrm{~km} . \mathrm{km}-2$. The annual rainfall within the basin varied from 1369 to $1721 \mathrm{~mm}$ and the average temperature compensated from 27.0 to $27.3^{\circ} \mathrm{C}$. The predominant soil use is the natural form, representing $76.93 \%$ of the basin's extension.

Keywords: hydrological behavior, drainage density, GIS.

\section{Introdução}

O conhecimento de uma determinada área torna-se indispensável para estimular reflexões, sobre os impactos ambientais sofridos, os aspectos sociais e econômicos do local, bem como para diagnosticar necessidades de gestão e planejamento (Santos et al., 2013). Em relação ao gerenciamento de bacias hidrográficas, se torna indispensável o conhecimento de suas características físicas e as diversas formas de uso e ocupação da terra, que podem afetar os recursos naturais, principalmente quando as fragilidades da área são desconhecidas (Medeiros et al., 2014). A aplicação de parâmetros morfométricos em bacias hidrográficas traz resultados quantitativos relevantes para maximizar a compreensão e a interpretação preliminar do comportamento hidrológico e geomorfológico da área estudada (Silva et al., 2014a). Os elementos físicos que relacionam as configurações da bacia hidrográfica com o seu comportamento hidrológico fornecem informações para o planejamento e para o manejo integrado das bacias hidrográficas (Nascimento et al., 2012). A caracterização topográfica das classes de declividade, forma do relevo, escoamento superficial, rede de drenagem e área de preservação permanente são fundamentais para estimar as suas condições de conservação de bacias hidrográficas (Rodrigues et al., 2011).

0 rio Farinha é um afluente da margem esquerda do rio Tocantins, possuindo uma importância muito grande para toda a região central do país (Marques, 2012). Segundo o mesmo autor o rio Farinha motivou a criação do Parque Nacional da Chapada das Mesas, como forma de proteger a paisagem da construção de duas pequenas centrais hidroelétricas em estudo nas cachoeiras do Prata e de São Romão, ambas no rio Farinha. No interior do Parque Nacional da Chapada das Mesas, existem muitas nascentes de rios, que abastecem três bacias hidrográficas importantes, a do Parnaíba, Araguaia/Tocantins e do São Francisco. 0 mapeamento dos parâmetros morfométricos e do padrão de uso da terra através das geotecnologias auxiliam na caracterização da dinâmica hídrica de uma bacia hidrográfica (Pereira et al., 2014).

0 uso de técnicas de sensoriamento remoto e Sistemas de Informações Geográficas (SIG) são importantes na elaboração de estudos hidrológicos, possibilitando a representação dos diversos parâmetros de forma distribuída, onde a realização desses estudos em bacias hidrográficas surgem da necessidade em si compreender o funcionamento do balanço hídrico e dos processos que controlam o movimento da água e seus 
prováveis impactos sobre a quantidade e a qualidade da água (Andrade et al., 2013).

Assim, é de grande importância para gestores e pesquisadores o desenvolvimento de estudos e pesquisas que visam a caracterização de bacias hidrográficas para subsidiar com informações e dados, programas de manejo integrado dessas áreas, que são ideais para diagnosticar, avaliar e planejar o uso dos recursos naturais.

O objetivo desse trabalho foi obter as características morfométricas, utilizando técnicas de geoprocessamento e sensoriamento remoto, e avaliar as condições climáticas e de uso do solo da bacia hidrográfica do rio farinha, analisando as implicações dos parâmetros morfométricos na funcionalidade da bacia e gerando informações e dados que sirvam de ferramenta preliminar para a gestão de recursos hídricos no estado do Maranhão.

\section{Material e Métodos}

0 presente estudo foi realizado na bacia hidrográfica do rio Farinha, localizada em terras dos municípios de Carolina, Estreito, São Pedro dos Crentes, Feira Nova do Maranhão e Riachão, na região sudoeste do estado do Maranhão (Figura 1). Conforme a estimativa populacional do Instituto Brasileiro de Geografia e Estatísticas (IBGE, 2016), tais municípios totalizam uma população de 92.554 habitantes.

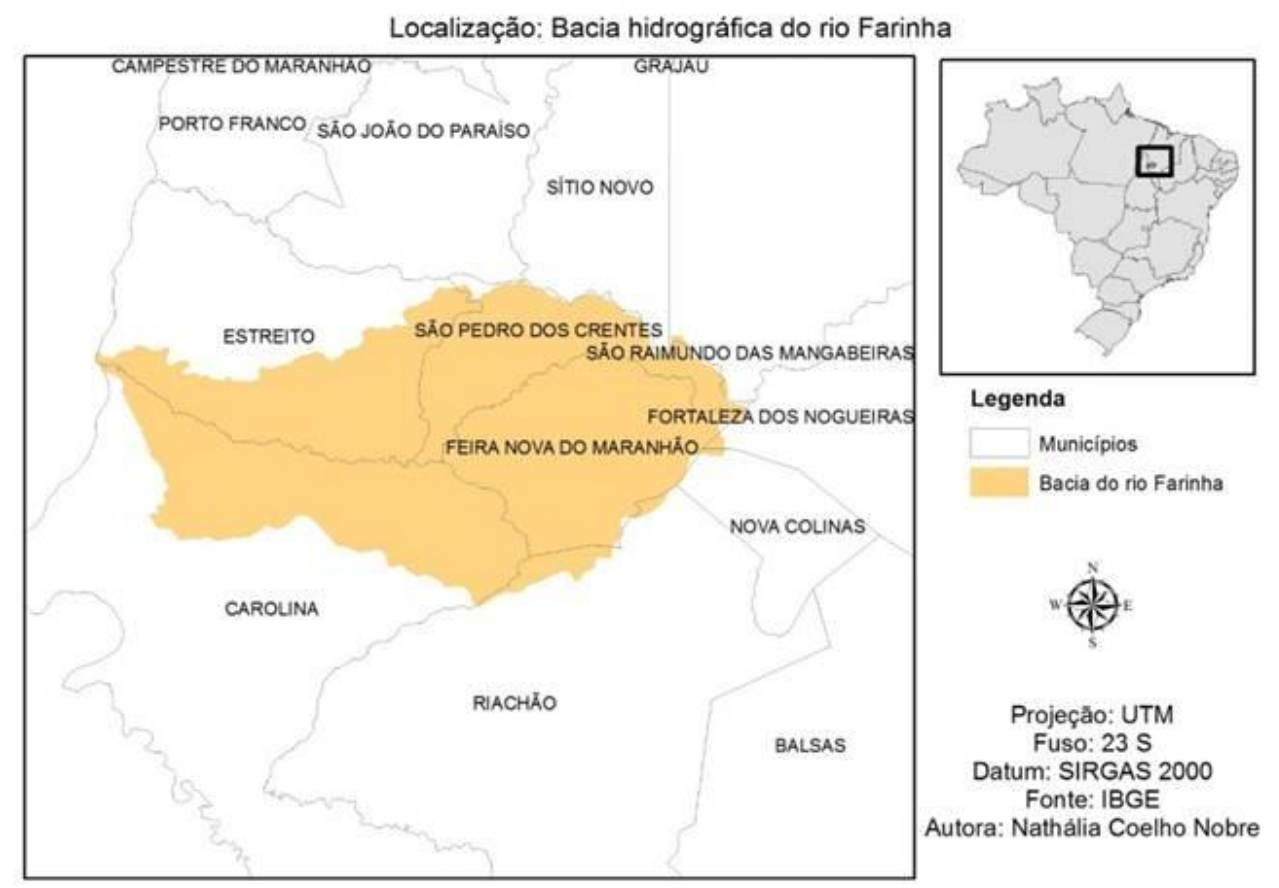

Figura 1. Localização da bacia hidrográfica do rio Farinha.

A bacia abrange parte do Parque Nacional da Chapada das Mesas, área de prioridade extremamente alta para conservação da biodiversidade, que abriga e protege nascentes e cursos d'água de diversos rios e possui abundância de espécies da fauna e flora. A bacia hidrográfica em questão inserese na bacia do rio Tocantins e compreende uma área de 5255,79 km², 
tendo como rio principal o rio Farinha, afluente da margem esquerda do rio Tocantins. Conforme base cartográfica digital disponibilizada pelo Ministério do Meio Ambiente (MMA, 2016), a bacia apresenta vegetação típica de Cerrado. Com relação aos solos (Figura 2), ha ocorrência de Neossolo Quartzarênico, Latossolo Amarelo, Nitossolo Vermelho e Neossolo Flúvico (MMA, 2016).

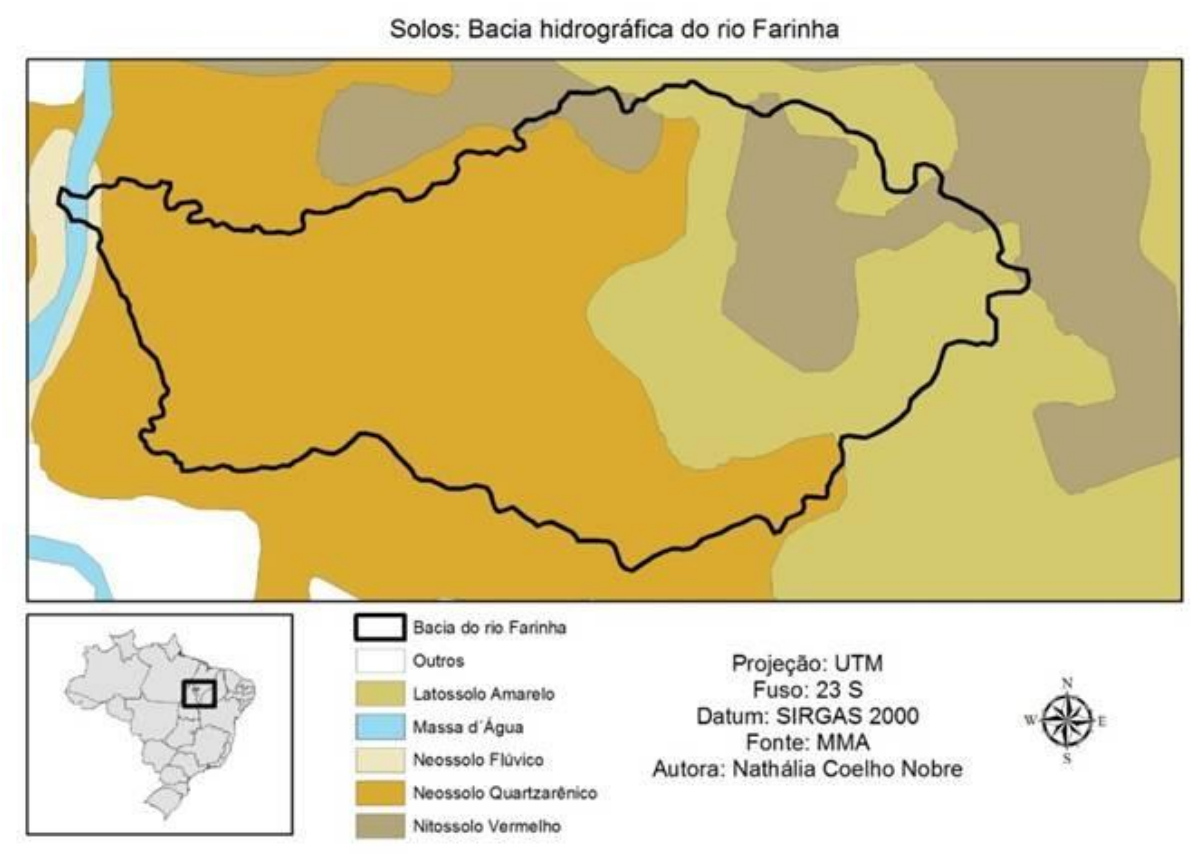

Figura 2. Solos da bacia hidrográfica do rio Farinha.

Segundo a classificação climática de Koppen, o clima predominante na região é o Aw - clima tropical com estação seca de inverno, ou seja, inverno seco e chuvas máximas no verão. Com base em registros mensais da Estação Meteorológica do município de Carolina, disponibilizados pelo Instituto Nacional de Meteorologia (INMET), para o período de 2001 a 2015, a precipitação média anual foi de $1762 \mathrm{~mm}$, sendo 2011 o ano mais chuvoso com uma precipitação total de $2282 \mathrm{~mm}$, e 2015 sendo o ano mais seco com $1243 \mathrm{~mm}$ de precipitação total. A temperatura média anual deste período foi de $27,47^{\circ} \mathrm{C}$, a média anual das mínimas foi de $22,8^{\circ} \mathrm{C}$ e das máximas $33,5^{\circ} \mathrm{C}$. $\mathrm{O}$ ano de 2010 foi considerado o mais quente, com temperatura média anual de $28,1^{\circ} \mathrm{C}$.
A estação de trabalho utilizada foi um notebook com disco rígido de $320 \mathrm{~GB}$, memória de $2 \mathrm{~GB}$ e processador Intel Atom Dual Core, 1.60 GHz. Os procedimentos metodológicos foram executados por meio da utilização do Sistema de Informação Geográfica da ESRI, ArcMap 10.1, para o processamento e obtenção dos dados.

A base hidrográfica foi obtida junto a Diretoria de Serviço Geográfico (DSG) do Exército Brasileiro, através das cartas topográficas MI-1188Babaçulândia e MI-1189-Carolina, na escala de 1:100.000, vetorizadas na plataforma do Spring. Os arquivos no formato shapefile obtidos foram utilizados na determinação das características geométricas e da rede de drenagem da bacia, na plataforma do ArcMap 10.1. Os dados do Shuttle Radar 
Topographic Mission (SRTM) foram utilizados no levantamento das características de relevo da bacia, como altitude e declividade média, foram obtidos junto a United States Geological Survey (USGS), com informações disponíveis para a América do Sul, apresentando resolução espacial de 30 m. Para a caracterização climática da bacia hidrográfica, foram utilizados registros mensais de precipitação total $(\mathrm{mm})$ e temperatura média $\left.{ }^{\circ} \mathrm{O}\right)$, no período de 2005 a 2015, das estações meteorológicas de Imperatriz, Carolina, Balsas e Araguaína. Os dados históricos foram obtidos junto ao INMET. Para a caracterização de uso e ocupação do solo da bacia, foram utilizados dados do projeto TerraClass, desenvolvido em 2013, no qual foi realizado o mapeamento do uso e cobertura da terra do bioma Cerrado, utilizando como fonte de informação imagens do satélite
Landsat 8. Os arquivos foram obtidos junto ao Instituto Nacional de Pesquisas Espaciais (INPE), no formato shapefile.

As classes de uso da terra estão segmentadas em áreas naturais, áreas antrópicas, corpos d'água e áreas não observadas. As áreas naturais são representadas pelas áreas florestais, áreas não florestais (formações savânica e campestre) e áreas naturais não vegetadas. As áreas antrópicas foram divididas em agricultura anual, agricultura perene, silvicultura, área urbana, mineração, mosaico de ocupações, pastagem e solo exposto. Áreas não observadas compreendem respostas espectrais às nuvens $\mathrm{e}$ queimadas. As características morfométricas podem ser divididas em: características geométricas, características do relevo e características da rede de drenagem (Tabela 1 ).

Tabela 1. Características morfométricas de bacias hidrográficas

\begin{tabular}{cl}
\hline Características Morfométricas & \multicolumn{1}{c}{ Tipo de Análises } \\
\hline & Área total \\
& Perímetro total \\
Características geométricas & Coeficiente de compacidade (Kc) \\
& Fator de forma (F) \\
& Índice de circularidade (IC) \\
& Padrão de drenagem \\
\hline & Orientação \\
& Declividade mínima \\
& Declividade máxima \\
& Altitude mínima \\
& Altitude média \\
& Altitude máxima \\
& Declividade média do curso d'água principal \\
\hline \multirow{2}{*}{ Características da rede de } & Comprimento do curso d'água principal \\
drenagem & Comprimento total dos cursos d'água \\
& Densidade de drenagem (Dd) \\
& Ordem dos cursos d'água \\
\hline
\end{tabular}

Baseados nessa segmentação foram escolhidos doze parâmetros para a análise morfométrica da bacia. Os parâmetros utilizados, com seus respectivos símbolos, fórmulas e unidades de medida encontram-se descritos na Tabela 2 . 
As fórmulas para obtenção dos atributos morfométricos e fisiográficos empregados na caracterização da Bacia Hidrográfica podem ser encontradas em
(Veiga et al., 2013; Moreli et al., 2014; Mioto et al., 2014; Guerra et al., 2015; Trentin et al., 2015; Abud et al., 2015).

Tabela 2. Parâmetros morfométricos

\begin{tabular}{|c|c|c|c|}
\hline Características & Abreviação & Fórmula & Unidade \\
\hline Área total & $\mathrm{A}$ & - & $\mathrm{km}^{2}$ \\
\hline Perímetro total & $P$ & - & $\mathrm{km}$ \\
\hline Fator de Forma & $\mathrm{F}$ & $\mathrm{F}=\frac{A}{L^{2}}$ & - \\
\hline $\begin{array}{l}\text { Coeficiente de } \\
\text { compacidade }\end{array}$ & Kc & $\mathrm{Kc}=0,28 \times \frac{p}{\sqrt{A}}$ & - \\
\hline $\begin{array}{c}\text { Índice de } \\
\text { circularidade }\end{array}$ & IC & $\mathrm{IC}=\frac{12,57 \mathrm{X} A}{p^{2}}$ & - \\
\hline $\begin{array}{c}\text { Densidade } \\
\text { hidrográfica }\end{array}$ & $\mathrm{Dh}$ & $\mathrm{Dh}=\frac{N}{A}$ & $\begin{array}{c}\text { Canais.km } \\
2\end{array}$ \\
\hline Declividade média & - & - & $\mathrm{m} \cdot \mathrm{m}^{-1}$ \\
\hline Altitude média & - & - & $\mathrm{m}$ \\
\hline $\begin{array}{l}\text { Amplitude } \\
\text { altimétrica }\end{array}$ & - & - & $\mathrm{m}$ \\
\hline $\begin{array}{c}\text { Ordem dos cursos } \\
\text { d'água }\end{array}$ & - & - & - \\
\hline $\begin{array}{l}\text { Densidade de } \\
\text { drenagem }\end{array}$ & $\mathrm{Dd}$ & $\mathrm{Dd}=\frac{\sum L}{A}$ & $\mathrm{~km} \cdot \mathrm{km}^{-1}$ \\
\hline $\begin{array}{c}\text { Índice de } \\
\text { sinuosidade }\end{array}$ & Is & IS $=\frac{L}{D v}$ & - \\
\hline
\end{tabular}

em que,

A - Área da bacia, $\mathrm{km}^{2}$;

$\mathrm{L}$ - comprimento do eixo da bacia, $\mathrm{km}$

$\mathrm{P}$ - Perímetro da bacia, km

$\mathrm{N}$ - número de rios ou cursos d'água

$\sum \mathrm{L}$ - comprimento total dos drenos, $\mathrm{km}$

$\mathrm{L}$ - comprimento do canal principal, $\mathrm{km}$ e

Dv - distância vetorial do canal principal, $\mathrm{km}$.

Os dados necessários para os cálculos dos parâmetros analisados foram obtidos com o auxílio do SIG Arcmap 10.1, da ESRI. Na Tabela 3 estão descritos os métodos utilizados na obtenção.

Para a caracterização climática da bacia foram obtidas a precipitação e a temperatura anual média para as estações meteorológicas de Imperatriz,
Carolina, Balsas e Araguaína, no período de 2005 a 2015. Foi organizado um banco de dados com as informações de latitude, longitude, precipitação e temperatura anual média de cada estação, conforme a Tabela 4. Utilizando esse banco de dados, foi possível realizar a interpolação dos dados e a determinação da precipitação $(\mathrm{mm})$ e temperatura anual média $\left({ }^{\circ} \mathrm{C}\right)$ em toda a extensão da bacia, por meio dos métodos estatísticos Kriging e IDW do software ArcMap 10.1, que realizam a estimativa de um atributo através de outros atributos, nesse caso a estimativa da precipitação e da temperatura com base na latitude e longitude de cada ponto. 
Tabela 3. Obtenção dos parâmetros em SIG

\begin{tabular}{|c|c|}
\hline Parâmetros & Metodologia de aplicação \\
\hline Área/Perímetro & $\begin{array}{l}\text { Na tabela de atributos do shape da bacia, } \\
\text { cria-se uma coluna e utiliza-se a função } \\
\text { calcutate geometry, seleciona-se a opção } \\
\text { "área ou perímetro" e a unidade de medida. }\end{array}$ \\
\hline Comprimento do eixo da bacia & $\begin{array}{l}\text { Utiliza-se a ferramenta measure para traçar } \\
\text { uma reta da foz ao ponto mais longínquo da } \\
\text { bacia, é possível selecionar a unidade de } \\
\text { medida desejada. }\end{array}$ \\
\hline Número de rios ou cursos d'água & $\begin{array}{l}\text { Através da base de hidrografia utilizada na } \\
\text { ordenação dos cursos d'água, obtém-se o } \\
\text { número de rios da bacia. }\end{array}$ \\
\hline Comprimento total dos drenos & $\begin{array}{l}\text { Na tabela de atributos da base de hidrografia, } \\
\text { cria-se uma coluna e utiliza-se a função } \\
\text { calcutate geometry, seleciona-se a opção } \\
\text { length e a unidade de medida. Na funça } \\
\text { statistics obtém-se a soma do comprimento } \\
\text { dos canais. }\end{array}$ \\
\hline Comprimento do canal principal & $\begin{array}{l}\text { Na tabela de atributos da base de hidrografia, } \\
\text { cria-se uma coluna e utiliza-se a função } \\
\text { calcutate geometry, seleciona-se a opção } \\
\text { length e a unidade de medida. }\end{array}$ \\
\hline $\begin{array}{c}\text { Distância vetorial do canal } \\
\text { principal }\end{array}$ & $\begin{array}{l}\text { Utiliza-se a ferramenta measure para traçar } \\
\text { uma reta da nascente até a foz do canal, é } \\
\text { possível selecionar a unidade de medida } \\
\text { desejada. }\end{array}$ \\
\hline Declividade & $\begin{array}{l}\text { Utiliza-se o modelo digital de elevação } \\
\text { gerado a partir da base de dados SRTM e } \\
\text { aplica-se a função slope disponível na } \\
\text { extensão spatial analyst. }\end{array}$ \\
\hline Altitude & $\begin{array}{l}\text { Utiliza-se o modelo digital de elevação } \\
\text { gerado a partir da base de dados SRTM e } \\
\text { aplica-se a função contour disponível na } \\
\text { extensão spatial analyst. }\end{array}$ \\
\hline Ordem dos cursos d'água & $\begin{array}{l}\text { Seguindo a ordenação proposta pelo Método } \\
\text { de Strahler, a classificação é realizada de } \\
\text { modo manual, inserindo na tabela de } \\
\text { atributos do shape o número da ordem a que } \\
\text { pertencem os canais. }\end{array}$ \\
\hline
\end{tabular}


Tabela 4. Bancos de dados climáticos

\begin{tabular}{clccc}
\hline Cidade & Latitude & Longitude & $\begin{array}{c}\text { Precipitação } \\
(\mathbf{m m})\end{array}$ & $\begin{array}{c}\text { Temperatura } \\
\left({ }^{\circ} \mathbf{C}\right)\end{array}$ \\
\hline Imperatriz & -5.53 & -47.48 & 1.440 & 27,9 \\
Araguaína & -7.20 & -48.20 & 1.753 & 25,6 \\
Carolina & -7.34 & -47.46 & 1.765 & 27,5 \\
Balsas & -7.53 & -46.03 & 1.171 & 27,4 \\
\hline
\end{tabular}

\section{Resultados e Discussão}

A bacia hidrográfica do rio Farinha pode ser classificada como endorreica, por apresentar drenagens internas e não possuir escoamento até o mar. 0 padrão de drenagem formado pelos cursos d'água da bacia caracterizase como do tipo dendrítico, sendo típico de regiões onde predomina rocha de resistência uniforme (SILVA e TONELLO, 2014). A Tabela 5 apresenta os valores obtidos para a caracterização geométrica da bacia hidrográfica estudada.

Tabela 5. Características geométricas da bacia

\begin{tabular}{ccc}
\hline Parâmetro & Resultado & Unidade \\
\hline Área total & 5255,79 & $\mathrm{~km}^{2}$ \\
Perímetro total & 398,43 & $\mathrm{~km}$ \\
Fator de forma & 0,35 & - \\
Coeficiente de compacidade & 1,54 & - \\
Índice de circularidade & 0,42 & - \\
\hline
\end{tabular}

A bacia possui área de drenagem e perímetro de $5255,79 \mathrm{~km}^{2}$ e $398,43 \mathrm{~km}$, respectivamente, podendo ser classificada segundo Beck et al. (2013), como uma bacia média ou mesobacia, drenando as terras de cinco munícipios do sudoeste maranhense. 0 fator de forma e o índice de circularidade apresentaram resultados baixos. Esses valores indicam que a bacia possui uma forma alongada. A forma de uma bacia é determinada por parâmetros que relacionam a sua forma com figuras geométricas conhecidas, como o fator de forma, coeficiente de compacidade e índice de circularidade (Vilela e Mattos, 1975) Além disso, esses fatores influenciam o comportamento hidrológico da bacia e a tendência para maiores ou menores picos de enchentes (Schmitt e Moreira, 2015). Segundo Lorenzon et al. (2015) bacias com formato alongado apresentam valores elevados para o coeficiente de compacidade e pequenos para o índice de circularidade e fator de forma, caracterizand-sas assim como menos propensa à ocorrência de enchentes em condições normais de precipitação. Uma bacia com um fator de forma baixo é menos sujeita a enchentes que outra de mesmo tamanho, porém com maior fator de forma (Nardini et al., 2013). Mello e Silva (2013) comparam o comportamento da direção do escoamento superficial direto em uma bacia alongada e em uma bacia circular. Na bacia alongada o fluxo é distribuído ao longo do canal principal, produzindo cheias de menor impacto, na bacia circular ocorre concentração do escoamento superficial direto para um pequeno trecho do dreno principal, portanto com maior capacidade de proporcionar grandes cheias.

A bacia do rio Farinha apresentou 0,35 de fator de forma (valor 
baixo), 1,54 de coeficiente de compacidade (valor distante da unidade) e 0,42 de índice de circularidade (valor distante da unidade), indicando uma menor tendência a enchentes, correspondendo a uma bacia alongada, que não possui formato semelhante ao de uma circunferência, dessa forma apresentando maior tempo de concentração. Resultados semelhantes foram obtidos na microbacia de Ribeirão Água Fria na região de Bofete/SP e nas bacias hidrográficas do Alto Juruá, Acre (Nardini et al., 2013; Silva et al., 2014b); os autores destacam que quanto mais esses índices se distanciam da unidade e quanto mais próximos de zero for o $\mathrm{Kf}$, menor será a susceptibilidade a enchentes. Os índices calculados de $\mathrm{Kc}$, Kf e IC indicam que as bacias hidrográficas possuem formato alongado, isto é, quanto mais esses índices se afastam da unidade menor a chance da bacia hidrográfica possuir formato circular e, portanto, menor risco de enchentes (Silva et al., 2014b).

$$
\text { Pinto (2015) em estudo }
$$

realizado na bacia hidrográfica do rio Sararé, no estado de Mato Grosso, constatou que a bacia analisada apresentava baixa suscetibilidade às cheias, devido seu formato alongado, conforme os valores obtidos para o fator de forma $(0,02)$, índice de compacidade $(1,91)$ e índice de circularidade $(0,26)$. Alves et al. (2016) em seu estudo realizado na bacia hidrográfica de Ribeirão das Abóboras em Rio Verde/GO, constatou que a bacia analisada apresentava baixa suscetibilidade às cheias, devido seu formato alongado, conforme os valores obtidos para o fator de forma $(0,23)$, índice de compacidade $(1,55)$ e índice de circularidade $(0,41)$.

Uma bacia será mais suscetível a enchentes mais acentuadas quando seu Kc for mais próximo da unidade. Similarmente, o índice de circularidade tende para a unidade, à medida que a bacia se aproxima da forma circular e diminui quando a forma se torna alongada (Melo Neto e Mello, 2015).

Na Tabela 6 estão descritos os valores obtidos para as características de relevo da bacia do rio Farinha. A declividade média da bacia foi de $4^{\circ}$, sendo a máxima $62^{\circ}$ e a mínima $0^{\circ}$. Observa-se que a maior parte da bacia localiza-se em áreas de baixa declividade (Figura 3), favorecendo a infiltração de água no solo, devido a menor velocidade do escoamento superficial direto e ao maior tempo de concentração da precipitação nos drenos, indicando uma menor tendência a picos de enchentes.

A declividade do terreno é definida como a variação de altitude entre dois pontos do terreno em relação à distância que os separa (Ferrari et al., 2013). Assim, a declividade demonstra uma relação importante e também complexa com a infiltração, o escoamento superficial, a umidade do solo e a contribuição de água subterrânea ao escoamento do curso d'água (Silva et al., 2014). Quanto maior a declividade de uma bacia, maior a velocidade do escoamento superficial direto, menor o tempo de concentração, consequentemente maior os riscos de picos de enchentes. A ausência de cobertura vegetal, classe de solo e intensidade de chuvas, associada à uma maior declividade, resultará em uma maior velocidade de escoamento, menor infiltração no solo, causando enchentes mais pronunciadas na bacia Declividade pode ser considerada um importante fator de análise no estudo da fragilidade ambiental de um local, pois, os processos erosivos podem ser acelerados conforme o grau de inclinação da bacia (Schiavo et al., 2016). Outro aspecto importante é que a declividade média da bacia influencia a velocidade de escoamento da água sobre o solo e interfere na capacidade de armazenamento deste. 
Tabela 6. Características de relevo da bacia

\begin{tabular}{ccc}
\hline Parâmetro & Resultado & Unidade \\
\hline Declividade mínima & 0 & graus \\
Declividade média & 4,15 & graus \\
Declividade máxima & 62,45 & graus \\
Altitude mínima & 140 & $\mathrm{~m}$ \\
Altitude média & 346 & $\mathrm{~m}$ \\
Altitude máxima & 641 & $\mathrm{~m}$ \\
Amplitude altimétrica & 501 & $\mathrm{~m}$ \\
\hline
\end{tabular}

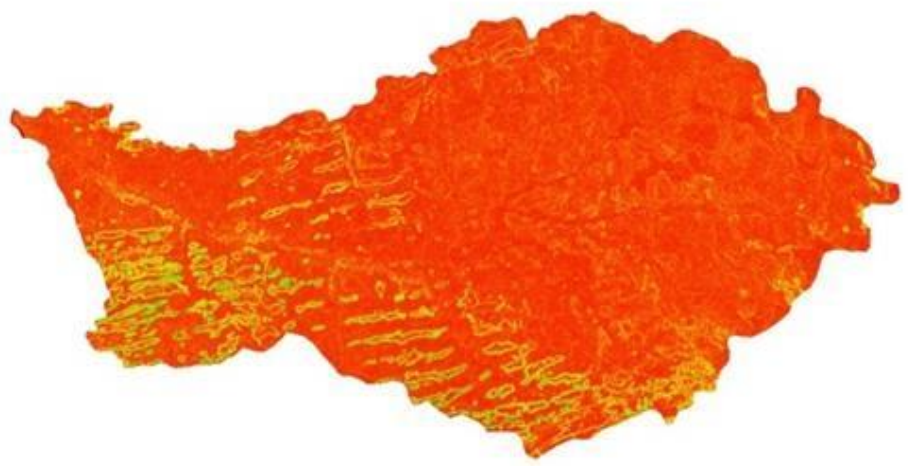

Legenda

Máxima: 62,45 graus

Minima: 0 grau

Figura 3. Declividade da bacia hidrográfica do rio Farinha.

A altitude média da bacia foi de 346 metros, sendo a máxima 641 metros e a mínima 140 metros, resultando em uma amplitude altimétrica de 501 metros. As áreas mais altas localizam-se nas nascentes e os pontos mais baixos na foz da bacia, dessa forma a diferença altimétrica direcionam a drenagem e o fluxo de escoamento. A Figura 4 apresenta o comportamento espacial da altitude por meio do Modelo Digital de Elevação.

Guadagnin e Trentin (2014) para a bacia hidrográfica do Arroio Arroio Caverá, localizada na região oeste do Rio
Grande do Sul, encontraram uma amplitude altimétrica de 289 metros, com menor cota de 77 metros e maior de 366 metros. Pinto (2015) em seu estudo realizado na bacia hidrográfica do rio Sararé, encontrou uma altitude mínima de 201 metros, média de 398 metros, máxima de 818 metros e amplitude altimétrica de 617 metros.

Segunda Silva e Tonello (2014) em elevadas altitudes, a temperatura é menor, necessitando de uma pequena quantidade de energia para evaporação da água, quando comparada a baixas altitudes, aonde a energia que chega é 
utilizada em sua totalidade. Em tais condições, a precipitação é maior que a evapotranspiração nas regiões de elevada altitude, resultando num excedente de água, responsável pelo abastecimento dos aquíferos e manutenção do fluxo das nascentes e cursos d'água. Grandes variações da altitude numa bacia acarretam diferenças significativas na temperatura média, a qual por sua vez, causa variações na evapotranspiração.
Souza et al. (2015), constatou maiores índices pluviométricos nas áreas de maior elevação e consequentemente os menores índices próximos à depressão sertaneja, porém ressaltou que esta relação altitude-precipitação não responde linearmente. Portanto, em função da alta variação de elevação, a bacia é sujeita a variações relevantes de temperatura e precipitação (Fraga et al., 2014).

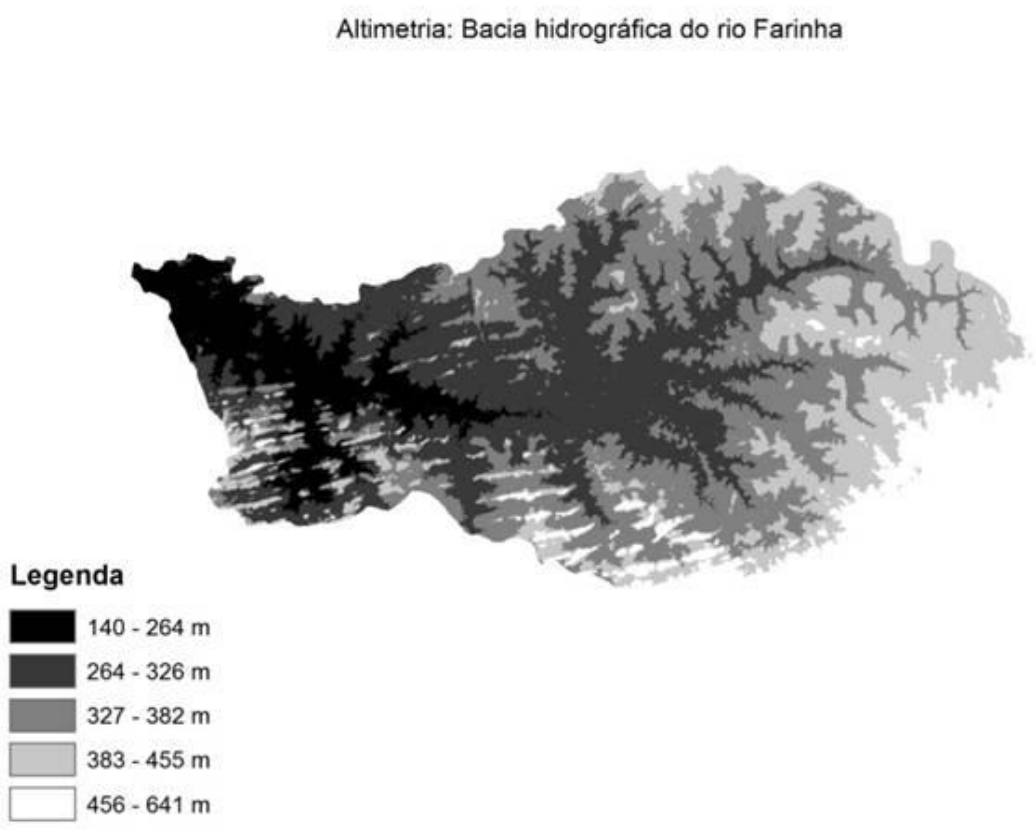

Figura 4. Altimetria da bacia hidrográfica do rio Farinha.

Na Tabela 7 estão descritos os valores obtidos para as características da rede de drenagem da bacia do rio Farinha. A bacia possui 382 cursos d'água, com uma densidade hidrográfica de 0,07 canais. $\mathrm{km}^{-}{ }^{2}$, dessa forma a bacia estudada apresenta poucos canais por unidade de área, possuindo baixa densidade hidrográfica, porém deve-se relembrar que a escala trabalhada foi de 1:100.000, consequentemente canais podem não ter sidos mapeados.

Tabela 7. Características da rede de drenagem da bacia

\begin{tabular}{ccc}
\hline Parâmetro & Resultado & Unidade \\
\hline Densidade hidrográfica & 0,07 & ${\text { Canais. } \mathrm{km}^{2}}^{2}$ \\
Densidade de drenagem & 0,42 & $\mathrm{~km}_{\mathrm{km}}{ }^{2}$ \\
Ordem dos cursos d'água & 3 & - \\
Índice de sinuosidade & 1,39 & - \\
\hline
\end{tabular}


A densidade hidrográfica (Dr) é a relação existente entre o número de rios, ou cursos de água, e a área da bacia hidrográfica. Sua finalidade é comparar a frequência ou a quantidade de cursos de água existentes em uma área de tamanho padrão (Rocha et al., 2014). A densidade hidrográfica relaciona o número de rios pela área da bacia, estabelecendo-se a quantidade de cursos d'água por $\mathrm{km}^{2}$. Sua importância é fundamental, pois deste parâmetro ocorre a representatividade do comportamento hidrográfico dentro de seus aspectos fundamentais: a magnitude da rede hidrográfica, indicando sua capacidade de gerar novos cursos d'água em função das características pedológicas, geológicas e climáticas da área (Freitas, 1952). A bacia do reservatório do Lobo, em São Paulo, caracterizada por Pereira (2013), apresentou densidade hidrográfica de 0,366 canais. $\mathrm{km}^{-}{ }^{2}$, dessa forma a bacia possui baixa densidade hidrográfica.

0 comprimento total dos cursos d'água foi de 2215,97 km, resultando em uma densidade de drenagem de 0,42 km. $\mathrm{km}^{2}$. Segundo Villela e Mattos (1975) este índice pode variar de $0,5 \mathrm{~km} \cdot \mathrm{km}^{-}{ }^{2}$ para bacias com drenagem pobre a 3,5 ou mais para bacias excepcionalmente bem drenadas, dessa forma a bacia estudada apresenta baixa capacidade de drenagem, outro fato também explicado pela pequena escala do trabalho.

Uma indicação razoável do grau de desenvolvimento de um sistema de drenagem é fornecida pelo índice chamado densidade de drenagem. A densidade de drenagem baixa permite inferir que o solo é permeável e a infiltração da água é mais eficiente (Nardini et al., 2013). De acordo com Queiroz et al. (2014) a densidade de drenagem esta relacionada diretamente com os processos climáticos atuantes na bacia hidrográfica, os quais influenciam o fornecimento e o transporte de material dentrítico ou indicam o grau de manipulação antrópica. A densidade de drenagem pode ser classifica em: baixa $(<$ $1,5)$, média $(1,5$ a 2,5$)$ e alta $(>2,5)$. A densidade de drenagem pode atuar como indicador da vulnerabilidade do solo (SILVA e TONELLO, 2014). O estudo da densidade de drenagem indica a maior ou menor velocidade com que a água deixa a bacia hidrográfica (Melo Neto e Mello, 2015). Diante disso, a bacia do bacia hidrográfica do rio Farinha-MA apresenta uma densidade de drenagem baixa, favorecendo a permanência da água na bacia por um período maior de tempo.

Leite et al. (2013) em estudo realizado na bacia hidrográfica do Rio Pacuí, no estado de Minas Gerais, encontraram valor aproximado de densidade de drenagem para a bacia analisada $\left(0,52 \mathrm{~km} \cdot \mathrm{km}^{-}{ }^{2}\right)$ concluindo que a bacia possui baixa capacidade de drenagem. Pereira (2013) obteve 0,495 $\mathrm{km} . \mathrm{km}^{-2}$ de densidade de drenagem, para a bacia hidrográfica do reservatório do Lobo, em Itirapina e Brotas, no estado de São Paulo. A densidade de drenagem (Dd) é obtida pela razão entre o comprimento dos canais e rios com a área da sub-bacia. Esse índice pode variar de 0,50 (drenagem pobre) a $3,50 \mathrm{~km} \mathrm{km-{ } ^ { 2 }}$ ou mais, em bacias com ótima drenagem, fornecendo indicativos da eficiência de drenagem (Villela e Mattos, 1975).

Ritela et al. (2013) em estudo realizado na bacia hidrográfica do Rio Aguapeí, no estado de, Mato Grosso, obteveram a densidade de drenagem de 0,58 a $0,81 \mathrm{~km} \cdot \mathrm{km}^{-}{ }^{2}$, constatando que a bacia possui baixa densidade de drenagem, pois há predominância de rochas sedimentares que deram origem a solos com alta capacidade de infiltração. O sistema de drenagem da bacia do rio Farinha, de acordo com a ordenação proposta pelo Método de Strahler, apresenta grau de ramificação de quinta 
ordem, demonstrando que a bacia é alimentada por vários tributários, em sua maioria rios de $1^{\text {a }}$ ordem. A hierarquização dos canais pode ser visualizada na Figura 5, ordem inferior ou igual a quatro é comum em pequenas bacias hidrográficas, sendo que quanto mais ramificada a rede de drenagem de uma bacia, mais eficiente será seu o sistema de drenagem. Pinto (2015) obteve o mesmo resultado para a bacia hidrográfica do rio Sararé, em Mato Grosso, em uma área de $3324,9 \mathrm{~km}^{2}$. Silva et al. (2014) para a bacia do rio Cacau, no Maranhão, encontraram grau de ramificação de 6 ${ }^{\underline{a}}$ ordem, em uma área de $917 \mathrm{~km}^{2}$, evidenciando que bacia apresenta-se bastante ramificada e que é abastecida por vários tributários.
0 índice de sinuosidade encontrado para a bacia do rio Farinha foi de 1,39. Logo, o canal fluvial em questão não é meândrico, pois para ser definido como meândrico o índice de sinuosidade deve ser igual ou superior a 1,5 e quanto mais este valor se afasta de 1,5 e se aproxima de 1 , mais retilíneo será canal, entretanto a existência de um canal natural totalmente retilíneo é impossível. Segundo Rodrigues et al. (2013a) o índice de sinuosidade próximo a 1,0 indica que os canais tendem a serem retilíneos, os valores superiores a 2,0 indicam que os canais tendem a serem tortuosos e os valores intermediários indicam formas transicionais, dessa forma a bacia estudada apresenta uma forma transicional entre canais retilíneos e os tortuosos.

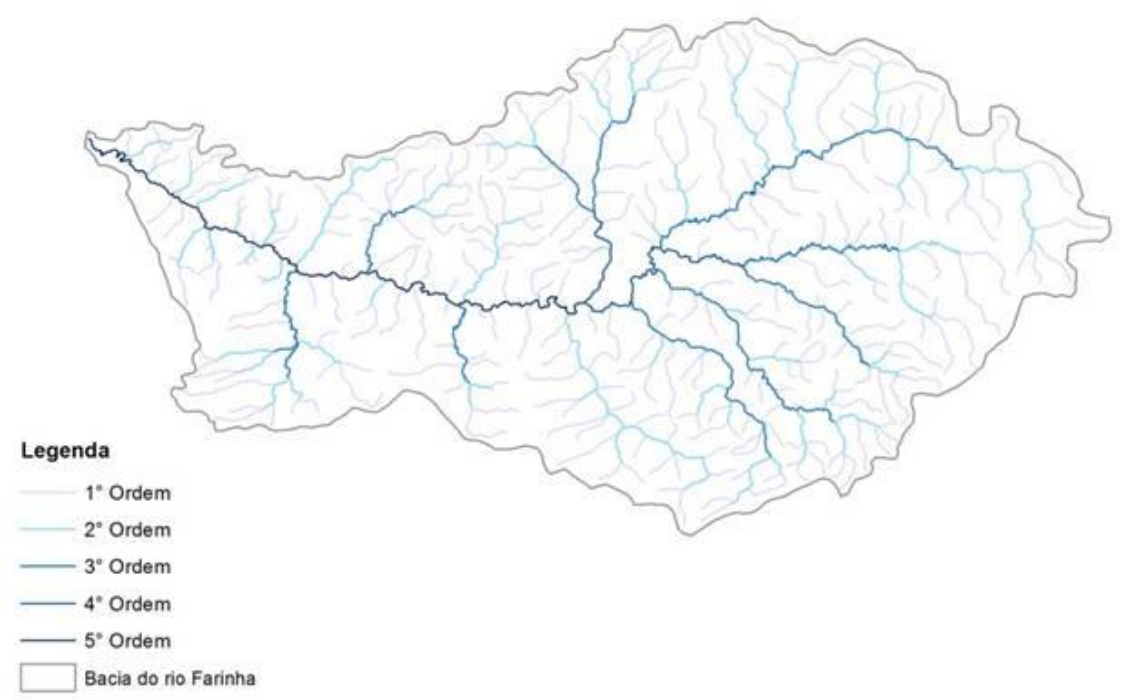

Figura 5. Ordem dos cursos d'água da bacia hidrográfica do rio Farinha.

A Tabela 8 apresenta a relação número de canais por ordem. A bacia hidrográfica do rio Farinha possui 292 afluentes de primeira ordem, demonstrando riqueza em nascentes; 69 afluentes de segunda ordem; 15 de terceira ordem, 5 de quarta ordem, e 1 de quinta ordem, sendo este o rio Farinha. 
Tabela 8. Relação número de canais por ordem

\begin{tabular}{cc}
\hline Ordem & Número \\
\hline $1^{\underline{a}}$ & 292 \\
$2^{\underline{a}}$ & 69 \\
$3^{\underline{a}}$ & 15 \\
$4^{\underline{a}}$ & 5 \\
$5^{\underline{a}}$ & 1 \\
\hline
\end{tabular}

\section{Características climáticas da bacia}

Pelo método estatístico do SIG utilizado para este trabalho, observa-se que a precipitação anual na bacia hidrográfica do rio Farinha varia de 1369 a $1721 \mathrm{~mm}$, com maior precipitação na porção oeste da bacia (Figura 6). 0 conhecimento das características de pluviométricas de uma bacia hidrográfica apresenta grande importância pois influencia na taxa de desagregação do solo por ação da precipitação e do escoamento laminar e concentrado, além dos processos de transferência dos sedimentos da bacia vertente para a calha fluvial e processos de erosão e deposição que ocorrem na calha fluvial (Minella e Merten, 2011). A temperatura média compensada comporta- se variando de 27,0 a $27,3^{\circ}$ C (Figura 7), apresentando pouca variação na extensão da bacia. A alteração da temperatura superficial terrestre é resultado do equilíbrio e distribuição da energia à superfície terrestre e está diretamente relacionada com as mudanças no uso e ocupação do solo da bacia, configurando-se como um indicador de interferência no solo, vegetação e na paisagem local (Pereira et al., 2012). Galvíncio et al. (2007) em estudo realizado na bacia hidrográfica do rio Brígida, localizada no sertão do estado de Pernambuco, utilizando o método estatístico da krigagem, encontraram uma precipitação dentro da bacia dividida em quatro faixas de volume precipitado, variando de 624 a $961 \mathrm{~mm}$, com maior precipitação na região da chapada do Araripe. A temperatura comporta-se variando de 23,7 a $26,0 \stackrel{\circ}{\circ}$.)

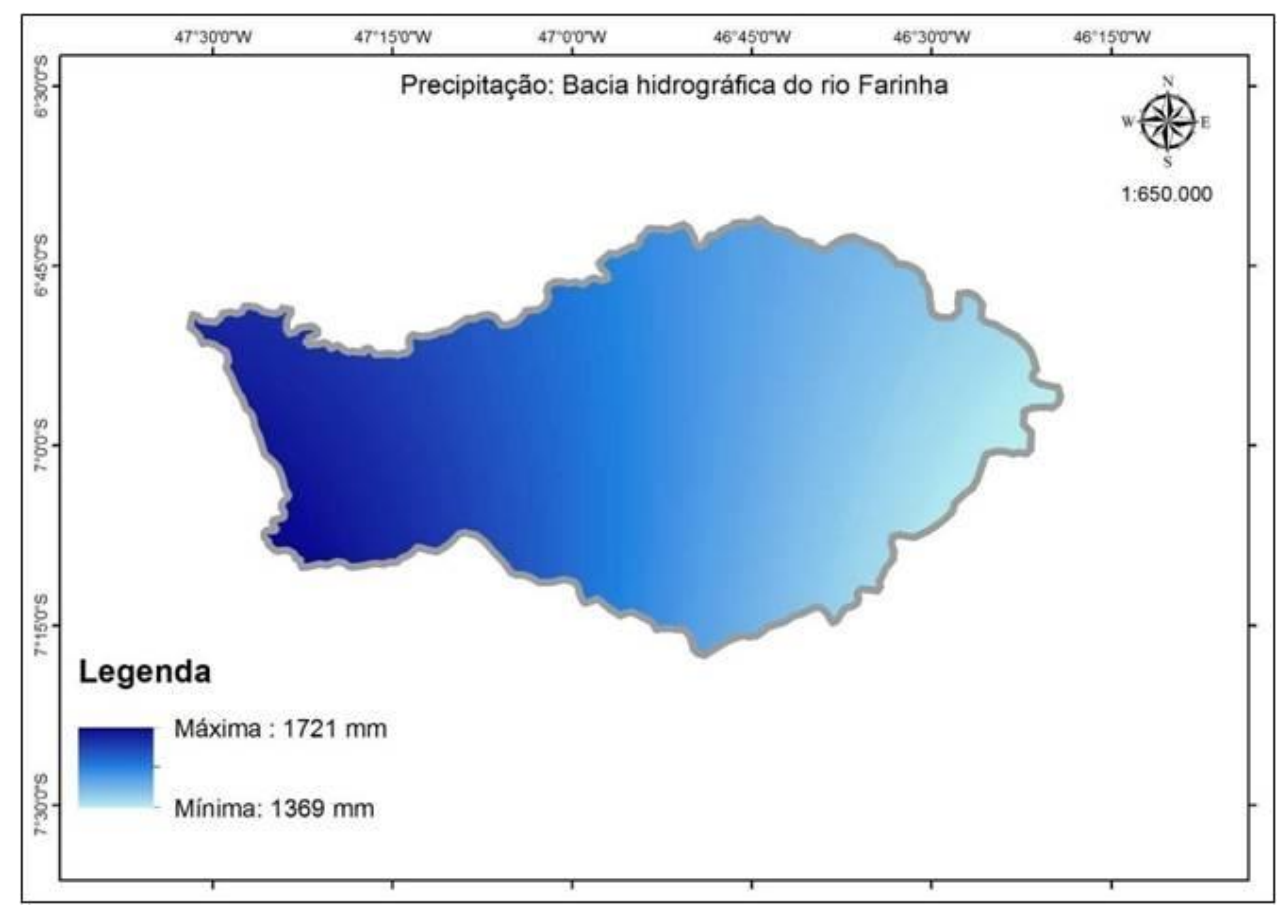

Acta Iguazu, Cascavel, v.9, n.1, p. 11-34, 2020 
Figura 6. Precipitação da bacia hidrográfica do rio Farinha.

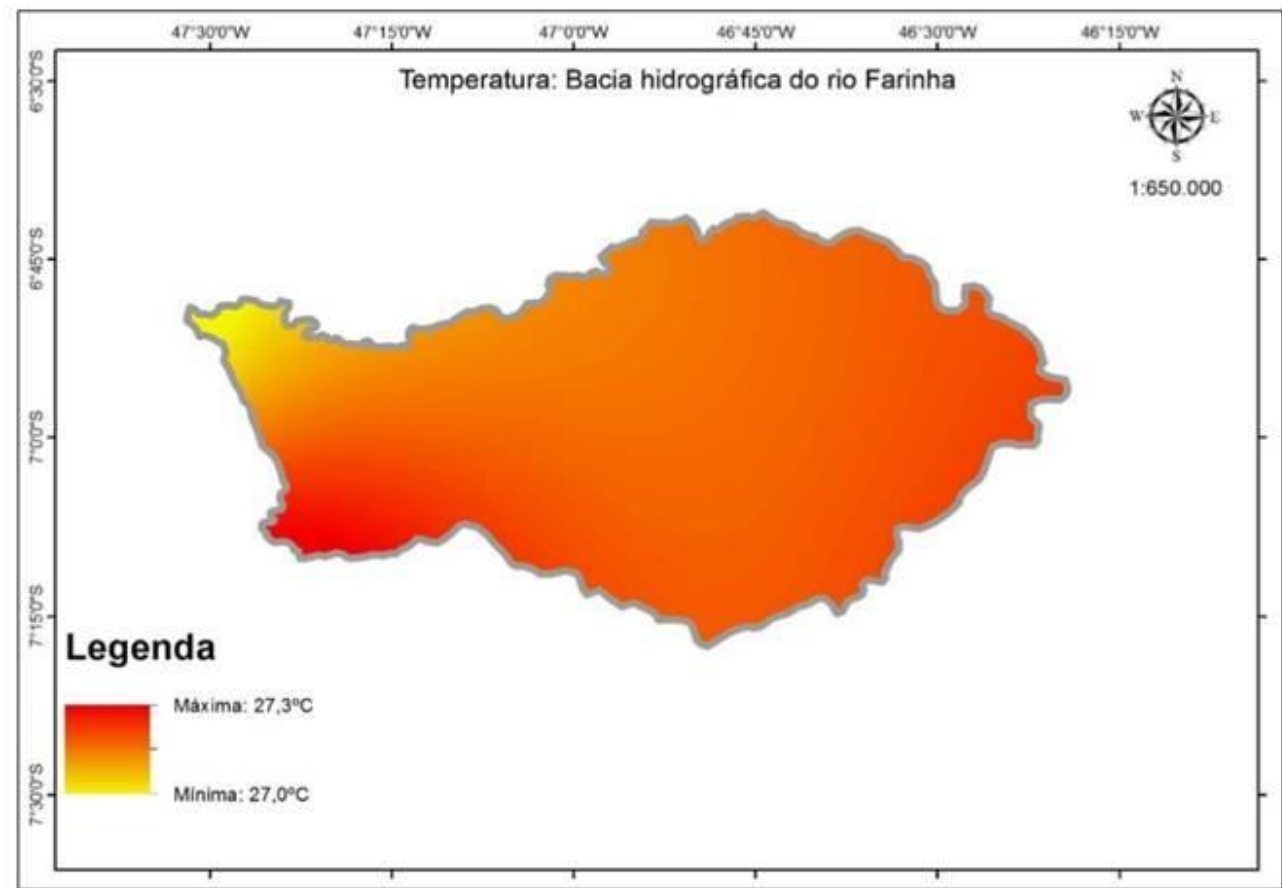

Figura 7. Temperatura da bacia hidrográfica do rio Farinha.

A bacia hidrográfica do rio Farinha encontra-se inserida predominantemente em área rural e apresenta 10 categorias de uso do solo. $\mathrm{Na}$ Tabela 9 encontram-se os valores de área e a porcentagem das classes de uso do solo. 0 principal uso da terra na bacia é a forma natural (Figura 8), ocupando $76,93 \%$, que corresponde a áreas com florestas, formações savânicas e campestres, demonstrando que a paisagem da bacia se encontra preservada, prevenindo o processo erosivo e o transporte de sedimentos para os cursos d'água. Conforme base cartográfica digital disponibilizada pelo MMA (2016), a bacia apresenta vegetação típica de Cerrado. A ausência de cobertura vegetal, classe de solo e intensidade de chuvas, associada à uma maior declividade, resultará em uma maior velocidade de escoamento, menor infiltração no solo, causando enchentes mais pronunciadas na bacia.
Segundo Sebusiani e Bettine (2011) a intensidade de uso e ocupação de uma bacia hidrográfica está fortemente associada ao nível de impermeabilização do solo dessa mesma região e por isso esses aspectos devem ser trabalhados de forma conjunta. 0 mapeamento das informações é um recurso muito utilizado para tornar mais evidente os padrões de uso e ocupação dos espaços.

As pastagens ocupam 1151,90 $\mathrm{km}^{2}$ da área da bacia, correspondendo a $21,92 \%$, geralmente compostas por uma única espécie de gramínea (Brachiaria), sendo assim a segunda classe mais frequente na bacia. A silvicultura corresponde a $0,31 \%$ da área da bacia, ocupando $16,17 \mathrm{~km}^{2}$, sendo áreas compostas por apenas uma espécie de interesse comercial. As demais classes ocupam 44,35 $\mathrm{km}^{2}$, correspondendo a $0,84 \%$ da área da bacia. 
Tabela 9. Uso e ocupação do solo na bacia do rio Farinha

\begin{tabular}{ccc}
\hline Classe & Área $\mathbf{( k m}^{\mathbf{2}} \mathbf{)}$ & Porcentagem (\%) \\
\hline Agricultura anual & 5,33 & $0,10 \%$ \\
Água & 16,28 & $0,31 \%$ \\
Mosaico de ocupações & 1,23 & $0,02 \%$ \\
Não observado & 7,89 & $0,15 \%$ \\
Não vegetado & 2,06 & $0,04 \%$ \\
Natural & 4043,47 & $76,93 \%$ \\
Pastagem & 1151,90 & $21,92 \%$ \\
Silvicultura & 16,17 & $0,31 \%$ \\
Solo exposto & 10,04 & $0,19 \%$ \\
Urbano & 1,52 & $0,03 \%$ \\
\hline
\end{tabular}

0 monitoramento ambiental em bacias hidrográficas busca avaliar aspectos importantes que caracterizam mudanças no uso da terra e uso do solo, possibilitando avaliar os efeitos das atividades humanas nos ecossistemas (Bertossi et al., 2013). De acordo com Coelho et al. (2014) a melhor maneira de monitorar mudanças geomorfométrica da utilização dos solos predominantes de uma bacia hidrográfica é através de metodologias de sensoriamento remoto que permitem detectar e quantificar as modificações ocorridas na paisagem. A Figura 8 apresenta uso e ocupação do solo da bacia hidrográfica do rio Farinha.

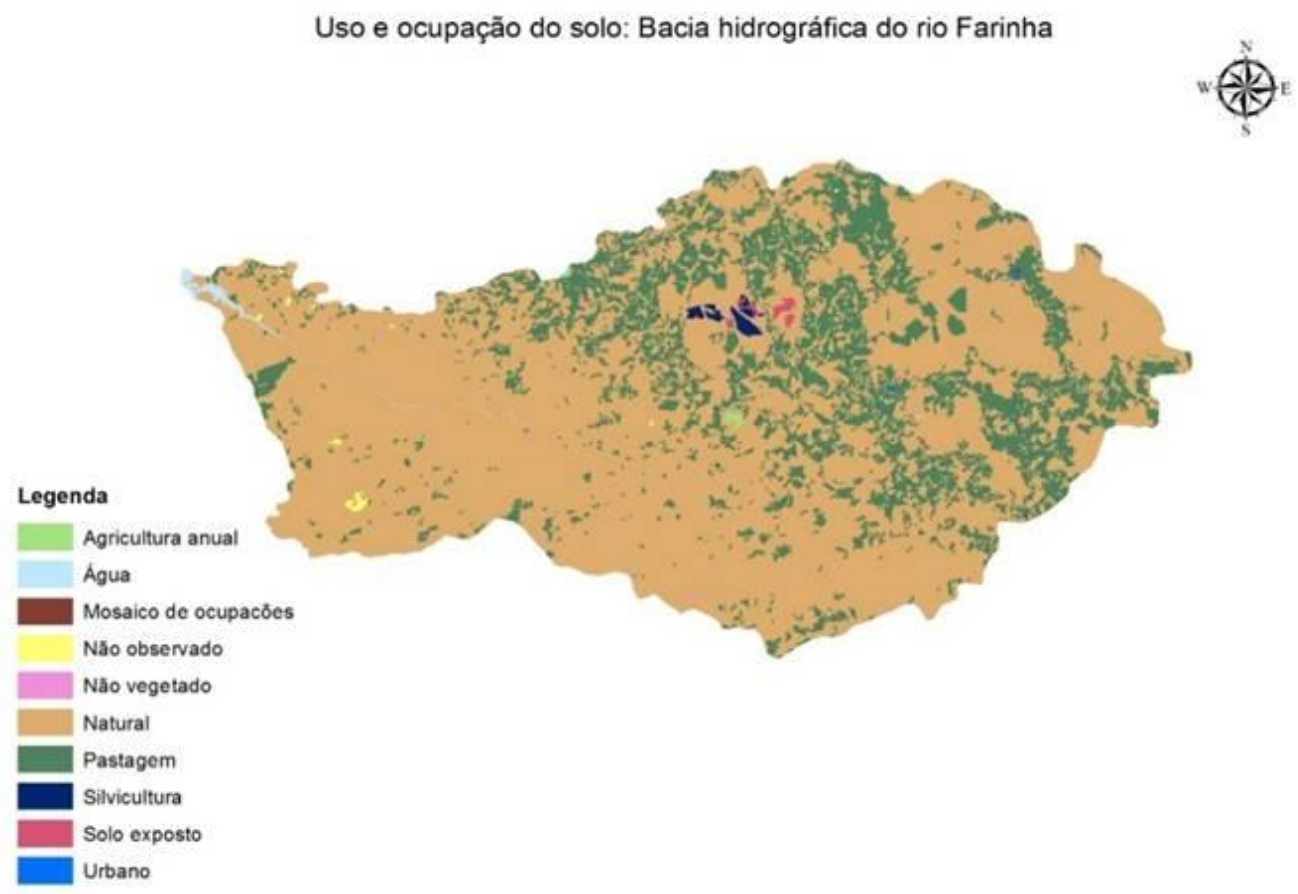

Figura 8. Uso e ocupação do solo da bacia hidrográfica do rio Farinha.

A cobertura vegetal de uma bacia hidrográfica, principalmente as florestas densas, interferem na velocidade do escoamento superficial, permitindo maior infiltração e favorecendo a retenção de água no sistema, sendo considerada um fator importante na definição do padrão de movimento da água em uma bacia (Rodrigues et al., 2013b; Coutinho et al., 
2013). Nos estudos morfodinâmicos a cobertura vegetal assume um papel de destaque atuando como elemento estabilizador e algumas variáveis (clima, geologia, geomorfologia, solo) podem sofrer o efeito da alteração na cobertura vegetal (Almeida et al., 2012). Além disso, Pinheiro et al. (2014) comprovaram em seus estudos que as atividades desenvolvidas e o uso do solo nas bacias hidrográficas podem afetar a qualidade dos recursos hídricos de uma região.Vale ressaltar que mudanças no regime pluviométrico podem interferir diretamente na resposta da cobertura vegetal e, consequentemente, nos componentes do ciclo hidrológico (Cunha et al., 2012).

Preservar a cobertura vegetal é condição fundamental para a conservação dos recursos hídricos uma vez que a vegetação tem importante função na proteção e na manutenção de nascentes e cursos d'água. Sua retirada descaracteriza os ambientes originais dos rios e interfere no balanço hídrico das bacias hidrográficas (Silva et al., 2014c). Pois de segundo Perazzoli et al. (2013) o uso do solo pode afetar os processos hidrológicos e a erosão do solo na bacia, causando impactos no transporte de sedimentos, no escoamento superficial,

\section{Conclusão}

Considerando os resultados encontrados nesse estudo foi possível estabelecer as seguintes conclusões:

- A caracterização geométrica da bacia estudada aponta para uma bacia alongada, indicando uma menor propensão a picos de enchentes, pois a bacia possui maior tempo de concentração, sendo comprovado pelo fator de forma, coeficiente de compacidade e índice de circularidade;

- A caracterização da rede de drenagem indica que a bacia na vazão máxima de cheia, recarga subterrânea, umidade do solo, além de afetar vários outros processos de maneira intensa.

Nas dez categorias de uso e cupação do solo utilizadas no estudo, nota-se que a bacia do rio farinha encontra-se bastante preservada, pois a vegetação natural é a classe predominante ocupando 76,93\% da área, já a agricultura ocupa apenas 0,10\% da área sendo constituída de pequenas propriedades onde é desenvolvida a agricultura familiar. De acordo com Gonçalves et al. (2011) as áreas cuja cobertura correspondeu à floresta proporcionam proteção muito forte ao impacto das chuvas erosivas, motivo pelo qual foi atribuída a condição (baixa fragilidade), enquanto que as áreas cobertas por cerrado ou complexo de vegetação conferem um grau mais baixo de proteção quando comparadas com as áreas de floresta. Santos (2014) em estudo realizado na bacia do riacho Açaizal, no Maranhão, identificou a predominância de três classes, pastagem, agricultura permanente e capoeira, que juntas totalizam cerca de $77,49 \%$ da área da bacia. Constatando que a bacia se encontrava predominantemente antropizada.

possui baixa densidade hidrográfica (relação canais por unidade de área) e baixa capacidade de drenagem;

- 0 sistema de drenagem da bacia do rio Farinha apresenta grau de ramificação de quinta ordem, demonstrando que a bacia é alimentada por vários tributários. 0 índice de sinuosidade aponta que os canais da bacia apresentam uma forma transicional entre o retilíneo e o tortuoso.

- A caracterização climática indica maior precipitação média anual na porção oeste da bacia, e temperaturas médias anuais bem 
próximas em toda a extensão da bacia.

- O uso da terra predominante é a forma natural, demonstrando que a paisagem encontra-se preservada, prevenindo o processo erosivo e o transporte de sedimentos para os cursos d'água;

- O conjunto de dados e informações encontradas servem de ferramenta preliminar na gestão dos recursos hídricos da bacia do rio Farinha/MA, e para a implantação de programas de manejo integrado dessas áreas, que são necessários para diagnosticar e planejar o uso dos recursos naturais.

\section{Referências}

ABUD, É. A.; LANI, J. L. ; ARAÚJO, E. A.; AMARAL, E. F.; BARDALES, N. G.; FERNANDES FILHO, E. I. Caracterização morfométrica das sub-bacias no município de Xapuri: subsídios à gestão territorial na Amazônia

Ocidental. Ambiente e Água-An Interdisciplinary Journal of Applied

Science, v. 10, n. 2, 2015. Disponível em: http://www.redalyc.org/html/928/928 38238017/. Acesso em: 17 dez. 2017.

ALMEIDA, N. V.; CUNHA, S.B.;

NASCIMENTO, F.R. A cobertura vegetal e sua importância na analise morfodinâmica da bacia hidrográfica do rio Taperoá - Nordeste do Brasil/ Paraíba. Revista Geonorte, Edição Especial, v.3, n.4, p. 365-378, jun .2012. Disponível em:

http://www.periodicos.ufam.edu.br/revi sta-geonorte/article/view/1953. Acesso em: 01 dez. 2017.

ALVES, W. S.; SCOPEL, I.; MARTINS, A. P.; MORAIS, W. A. Análise morfométrica da bacia do Ribeirão das Abóboras-Rio Verde (GO). Geociências (São Paulo), v.
35, n. 4, p. 652-667, 2016. Disponível em: http://www.ppegeo.igc.usp.br/index.ph p/GEOSP/article/view/9978. Acesso em: 13 dez. 2017.

ANDRADE, M. A.; DE MELLO, C. R.; BESKOW, S. Simulação hidrológica em uma bacia hidrográfica representativa dos Latossolos na região Alto Rio Grande, MG. Revista Brasileira de Engenharia Agricola e Ambiental-Agriambi, v. 17, n. 1, 2013. Disponível em: https://www.researchgate.net/profile/S amuel Beskow/publication/262429900 Hydrological simulation in a watershed with predominance of Oxisol in the $U$ pper Grande river region $\mathrm{MG}$ Brazil/links/53f1e6860cf2711e0c460d cf.pdf. Acesso em: 11 dez. 2017.

BECK, H.E.; The impact of forest regeneration on streamflow in 12 mesoscale humid tropical catchments. Hydrology and Earth System Sciences, v.17, p.2613-2635, Jul, 2013.

DOI:10.5194/hess-17-2613-2013.

Disponível em:

https://search.proquest.com/openview/ 33bc7f0488a759e9c58589b23590cb2b/ 1 ?pq-origsite $=$ gscholarecbl $=105724$. Acesso em: 15 dez. 2017.

BERTOSSI, A. P. A.; CECÍLIO, R. A.; NEVES, M. A., e DE GARCIA, G. O. Qualidade da água em microbacias hidrográficas com diferentes coberturas do solo no sul do Espírito Santo. Revista Árvore, v. 37, n. 1, 2013. Disponível em: http://www.redalyc.org/html/488/488 25658012/. Acesso em: 14 dez. 2017.

COELHO, V. H.; MONTENEGRO, S. M.; ALMEIDA, C. D. N.; DE LIMA, E. R.; NETO, A. R.; DE MOURA, G. S. Dinâmica do uso e ocupação do solo em uma bacia hidrográfica do semiárido brasileiro. Revista Brasileira de Engenharia Agricola e AmbientalAgriambi, v. 18, n. 1, 2014. Disponível 
em:

http://www.agriambi.com.br/revista/v1 8n01/v18n01a09.pdf. Acesso em: 14 dez. 2017.

COUTINHO, L. M.; ZANETTI, S. S.; CECÍLIO, R. A.; GARCIA, G. D. O.; XAVIER, A. C. Usos da terra e áreas de preservação permanente (APP) na bacia do Rio da Prata, Castelo-ES. Floresta e

Ambiente, v. 20, n. 4, p. 425-434, 2013. Disponível em:

https://www.researchgate.net/profile/R oberto Cecilio/publication/262625801 Land use and Permanent Preservation Areas PPA in the watershed of Rio da Prata Brazil/links/545e0f6f0cf2c1a63bf bfe58/Land-use-and-PermanentPreservation-Areas-PPA-in-thewatershed-of-Rio-da-Prata-Brazil.pdf. Acesso em: 11 dez. 2017.

CUNHA, J. E. B. L.; RUFINO, L. A. A.; SILVA, B. B.; CHAVES, I. B. Dinâmica da cobertura vegetal para a Bacia de São João do Rio do Peixe, PB, utilizando-se sensoriamento remoto. Revista Brasileira de Engenharia Agrícola e Ambiental, v.16, p.539-548, mai. 2012. Disponível em: https://www.researchgate.net/profile/I ana Rufino/publication/285644405 Din amica da cobertura vegetal para a Baci a de Sao Joao do Rio do Peixe PB utiliz ando-

se sensoriamento remoto/links/56d4fe c008ae2cd682b94451/Dinamica-dacobertura-vegetal-para-a-Bacia-de-SaoJoao-do-Rio-do-Peixe-PB-utilizando-sesensoriamento-remoto.pdf. Acesso em: 16 dez. 2017.

FERRARI, J.L.; SILVA, S. F.; SANTOS, A. R.; GARCIA, R.F. Análise morfométrica da sub-bacia hidrográfica do córrego Horizonte, Alegre, ES. Agrária - Revista Brasileira de Ciências Agrárias. v.8, n.2, p.181-188, abr-jun. 2013. Disponível em: http://www.redalyc.org/html/1190/11 9027922016/. Acesso em: $11 \mathrm{dez} .2017$.

FRAGA, M. S.; FERREIRA, R. G.; SILVA, F. B.; VIEIRA, N. P. A.; SILVA, D. P.; BARROS, F.M.; MARTINS, I. S. B. Caracterização morfométrica da bacia hidrográfica do rio Catolé Grande, Bahia, Brasil. Nativa, Sinop, v. 02, n. 04, p. 214-218, out./dez. 2014. Disponível em:

https://www.researchgate.net/profile/N ativa Pesquisas Agrarias E Ambientais/ publication/269874016 CARACTERIZAC AO MORFOMETRICA DA BACIA HIDRO GRAFICA DO RIO CATOLE GRANDE BA HIA BRASIL MORPHOMETRIC CHARAC TERIZATION OF CATOLE GRANDE RIV ER WATERSHED BAHIA STATE BRAZIL /links/549866440cf2eeefc30f9643.pdf. Acesso em: 18 dez. 2017.

FREITAS, R. O. Textura de drenagem e sua aplicação geomorfológica. Boletim Paulista de Geografia, v. 11, p. 53-57, 1952.

GALVÍNCIO, J. D.; SÁ, I. I. S.; MOURA, M. S. B.; RIBEIRO, J. G. Determinação das características físicas, climáticas e da paisagem da bacia hidrográfica do rio brígida com o auxilio de técnicas de geoprocessamento e sensoriamento remoto. Revista de Geografia, Recife, v. 24, n. 2, p.293-306, maio. 2007. Disponível em:

https://periodicos.ufpe.br/revistas/revi stageografia/article/view/228698. Acesso em: 17 dez. 2017.

GONÇALVES,G. G. G.; DANIEL, O.; COMUNELLO, E.; VITORINO, A.C.T.; ARAI, F. K. Determinação da fragilidade ambiental de bacias hidrográficas.

Floresta, Curitiba, PR, v. 41, n. 4, p. 797 808, out./dez. 2011. Disponível em: http://revistas.ufpr.br/floresta/article/v iew/25344. Acesso em: 14 dez. 2017. 
GUADAGNIN, P. M. A.; TRENTIN, R. Compartimentação Geomorfométrica da Bacia Hidrográfica do Arroio CaveráRS. Geo UERJ, v. 1, n. 25, p. 183-199, 2014. Disponível em: http://www.epublicacoes.uerj.br/index.php/geouerj/a rticle/view/10030. Acesso em: $14 \mathrm{dez}$. 2017.

GUERRA, S. M. S.; DA SILVA, A. M. R. B.; ARAÚJO, S. P.; CORRÊA, M. M.; DA SILVA, V. L.; SANTOS, B. R. T. Caracterização Morfométrica e Avaliação da Qualidade da Água da Bacia Hidrográfica de Bita, Ipojuca-PE (Morphometric characterization and assessment of water quality Hydrographic Basin of Bita, Ipojuca-PE). Revista Brasileira de Geografia Física, v. 8, n. 3, p. 759-775, 2015. Disponível em:

https://periodicos.ufpe.br/revistas/rbgf e/. Acesso em: 18 dez. 2017.

IBGE - INSTITUTO BRASILEIRO DE GEOGRAFIA E ESTATÍSTICAS. Cidades. 2010. Disponível em: < http://cidades.ibge.gov.br/xtras/perfil.p hp?codmun=210280. $>$. Acesso em: 13 dez. 2017.

LORENZON, A. S.; FRAGA, M. S.; MOREIRA, A. R.; ULIANA, E. M.; DA SILVA, D. D. Influência das características morfométricas da bacia hidrográfica do rio Benevente nas enchentes no município de Alfredo Chaves-

ES. Ambiente e Água-An Interdisciplinary Journal of Applied Science, v. 10, n. 1, 2015. Disponível em: http://www.redalyc.org/html/928/928 32874018/. Acesso em: $11 \mathrm{dez} .2017$.

MARQUES, A. R. Saberes geográficos integrados aos estudos territoriais sob a ótica da implantação do parque nacional da chapada das mesas, sertão de Carolina/MA. 2012. 199 f. Tese (Doutorado) - Curso de Doutorado em Geografia, Universidade Estadual
Paulista, Presidente Prudente, 2012.

Disponível em:

https://repositorio.unesp.br/handle/11 449/105036. Acesso em: 31 dez. 2017.

MEDEIROS, R. B; MIGUEL, A. S. M; CORONADO, C. A. B. X Fórum Ambiental da Alta Paulista (periódico eletrônico), v. 10, n. 2, p. 41-56. 2014. Disponível em: https://www.amigosdanatureza.org.br/ publicacoes/index.php/forum ambiental /article/view/860. Acesso em: $12 \mathrm{dez}$. 2017.

\section{MELLO, C. R.; SILVA, A. M. Hidrologia:} princípios e aplicações em sistemas agrícolas. Lavras: Ufla, 2013. 455 p.

MELO NETO, J.O.; MELLO, C.R. Levantamento das propriedades morfométricas da bacia hidrográfica do Ribeirão Vermelho com o uso de geoprocessamento. Global science and technology, Rio Verde, v.08, n.02, p.103 - 109, mai/ago. 2015. Disponível em: http://rv.ifgoiano.edu.br/periodicos/ind ex.php/gst/article/view/735. Acesso em: 14 dez. 2017.

MIOTO, C. L.; RIBEIRO, V. O.; SOUZA, D. M. Q.; PEREIRA, T. V.; ANACHE, J. A. A.; PARANHOS FILHO, A. C. Morfometria de bacias hidrográficas através de SIGs livres e gratuitos. Anuário do Instituto de Geociências, v. 37, n. 2, p. 16-22, 2014. Disponível em:

http://www.ppegeo.igc.usp.br/index.ph $\mathrm{p} /$ anigeo/article/view/5996. Acesso em: 04 dez. 2017.

MINELLA, J. P. G.; MERTEN, G.H. Monitoramento de bacias hidrográficas para identificar fontes de sedimentos em suspensão. Ciência Rural, Santa Maria, v.41, n.3, p.424-432, mar, 2011. Disponível em: http://revistas.bvsvet.org.br/crural/article/view/20823. Acesso em: 31 dez. 2017. 
MORELI, A. P.; PEREIRA, D. P.; DA SILVA, S. F. Caracterização morfométrica da sub-Bacia Hidrográfica do córrego Cancã, município de Venda Nova do ImigranteES, Brasil. Nucleus, v. 11, n. 2, p. 385395, 2014. Disponível em:

http://www.nucleus.feituverava.com.br/ index.php/nucleus/article/view/945. Acesso em: 11 dez. 2017.

MMA - MINISTÉRIO DO MEIO AMBIENTE. Download de dados geográficos. Disponível em: < http://mapas.mma.gov.br/i3geo/datado wnload.htm. >. Acesso em: 31 dez. 2017.

NARDINI, R. C.; POLLO, R. A.; CAMPOS, S.; BARROS,Z. X.; CARDOSO, L. G.; GOMES, L. N. Análise morfométrica e simulação das áreas de preservação permanente de uma microbacia hidrográfica. Irriga, Botucatu, v. 18, n. 4, p. 687-699, out-dez, 2013. Disponível em:

http://revistas.fca.unesp.br/index.php/i rriga/article/view/669. Acesso em: 08 dez. 2017.

NASCIMENTO, V. B.; WERLANG, M. K.; FACCO, R. Caracterização física da bacia hidrográfica do Arroio Cadena/Santa Maria-RS, Revista Geonorte, Edição Especial, v.3,n.4, p. 715-727, jun. 2012. Disponível em:

http://www.periodicos.ufam.edu.br/revi sta-geonorte/article/view/2038. Acesso em: 11 dez. 2017.

PERAZZOLI, M.; PINHEIRO, A.;

KAUFMANN, V. Efeitos de cenários de uso do solo sobre o regime hídrico e produção de sedimentos na bacia do Ribeirão Concórdia-SC. Revista Árvore, v. 37, n. 5, 2013. Disponível em: http://www.redalyc.org/html/488/488 29247008/. Acesso em: 11 dez. 2017.

PEREIRA, C.C.; MARIANO Z. F.; WACHHOLZ, F.; CABRAL, J.B.P. Análise da temperatura de superfície e do uso da terra e cobertura vegetal na bacia Barra dos Coqueiros (Goiás). Revista Geonorte, Edição Especial 2, v.2, n.5, p.1243 - 1255, 2012. Disponível em: http://periodicos.ufam.edu.br/index.php /revistageonorte/article/view/2576/23 80. Acesso em: 16 dez. 2017.

\section{PEREIRA, J.P. F.A. Caracterização morfométrica da bacia do Reservatório do Lobo (Broa) Itirapina e Brotas/SP e análise temporal dos usos da terra em sua área. $2013.47 \mathrm{f}$.} TCC (Graduação) - Curso de Engenharia Ambiental, Universidade de São Paulo, São Carlos, 2013. Disponível em: https://scholar.google.com.br/scholar?h l=pt-

BReas sdt $=0 \% 2 \mathrm{C} 5 \mathrm{eq}=$ Caracteriza $\% \mathrm{C} 3 \%$ A7\%C3\%A3o+morfom\%C3\%A9trica+da +bacia+do+Reservat $\%$ C3\%B3rio+do+Lo bo+\%28Broa $\% 29+$ Itirapina+e+Brotas $\%$ 2FSP+e+an\%C3\%A1lise+temporal+dos+ usos+da+terra+em+sua+\%C3\%A1rea.+e btnG $=$. Acesso em: 14 dez. 2017.

PEREIRA, J.S.; HENDGES, E.R.; MARION, F. Caracterização morfométrica e alteração nos padrões de uso e ocupação da terra na microbacia do arroio industrial, no município de Francisco Beltrão-PR, BR. Revista Geonorte, Edição Especial 4, v.5, n.16, p.76-81, jan/jun, 2014. Disponível em: http://tede.unioeste.br/handle/tede/16 62. Acesso em: 11 dez. 2017.

PINHEIRO, A.; SCHOEN, C.; SCHULTZ, J.; HEINZ, K. G. H.; PINHEIRO, I. G.; DESCHAMPS, F. C. Relação entre o uso do solo ea qualidade da água em Bacia Hidrográfica Rural no Bioma Mata Atlântica. Revista Brasileira de Recursos Hídricos, v. 19, n. 3, p. 127 139, 2014. Disponível em: https://www.researchgate.net/profile/I unia Schultz/publication/305192576 R elacao Entre o Uso do Solo e a Qualida 
de da Agua em Bacia Hidrografica Rura l no Bioma Mata Atlantica/links/593a5 4584585153206389619/Relacao-Entreo-Uso-do-Solo-e-a-Qualidade-da-Aguaem-Bacia-Hidrografica-Rural-no-BiomaMata-Atlantica.pdf. Acesso em: $14 \mathrm{dez}$. 2017.

\section{PINTO, V. R. Caracterização}

morfométrica e capacidade de uso da terra da bacia hidrográfica do rio Sararé, sudoeste do estado de Mato Grosso. 87 f. Dissertação (Mestrado) Curso de Ciências Ambientais, Universidade do Estado de Mato Grosso, Cáceres, 2015. Disponível em: http://portal.unemat.br/media/files/VA LCIR-ROGERIO-PINTO.pdf. Acesso em: 11 dez. 2017.

QUEIROZ, P. H.; SILVA, J. M. O.; SALES, M. C. L. Indicadores morfométricos como subsidio ao planejamento ambiental em um setor do médio curso da bacia hidrográfica do Rio Pacoti-CE. Revista Equador, v. 3, n. 1, p. 3-24, 2014. Disponível em:

http://www.ojs.ufpi.br/index.php/equa dor/article/view/1639. Acesso em: 14 dez. 2017.

RITELA, A.; CABRAL, I. D. L. L.; SOUZA, C. Disponibilidade de água e uso da terra na bacia hidrográfica do rio Aguapeí-Mato Grosso/Brasil. Enciclopédia Biosfera, Centro Científico Conhecer-Goiânia, v. 9, n. 17, p. 3358-3385, 2013. Disponível em:

http://conhecer.org.br/enciclop/2013b/ MULTIDISCIPLINAR/DISPONIBILIDADE. pdf. Acesso em: 11 dez. 2017.

ROCHA, R. M.; LUCAS, A. A. T.; ALMEIDA, C. A. P.; MENEZES NETO, E. L.; AGUIAR NETTO, A. O.Caracterização morfométrica da sub-bacia do rio PoximAçu, Sergipe, Brasil. Revista Ambiente e Água. v. 9 n. 2 Taubaté, apr. / jun. 2014. Disponível em: http://www.redalyc.org/html/928/928 31117009/. Acesso em: 01 dez. 2017.

RODRIGUES, J. O.; DE ANDRADE, E. M.; MENDONÇA, L. A.; DE ARAÚJO, J. C.; PALÁCIO, H. A. D. Q.; ARAÚJO, E. M. Respostas hidrológicas em pequenas bacias na região semiárida em função do uso do solo. Revista Brasileira de Engenharia Agricola e AmbientalAgriambi, v. 17, n. 3, 2013b. Disponível em:

http://observatorio.faculdadeguanambi. edu.br/wpcontent/uploads/2015/04/Rodirgueset-al-2013.pdf. Acesso em: 14 dez. 2017.

RODRIGUES, V. A.; CARDOSO, L. G.; POLLO, R. A.; RÉ, D. S.; PISSARRA, T. C. T.; VALLE JÚNIOR, R. F. D. Análise morfométrica da microbacia do Ribeirão das Araras-SP. Revista Científica Eletrônica de Engenharia Florestal, Garça, SP, v. 21, n. 1, p. 25-37, 2013a. Disponível em:

http://www.faef.revista.inf.br/imagens arquivos/arquivos destaque/mgtzDvrN U6dGKJ4 2013-4-29-16-24-39.pdf. Acesso em: 17 dez. 2017.

RODRIGUES, V. A.; FENNER, P. T.; AMARAL, L. P.; BANTEL, C. A.; IMAÑA E., J.; BLANCO, O. E. Degradação ambiental da microbacia do ribeirão Tamanduá em relação com sua morfometria. Revista Forestal Venezoelana, Merida, Venezuela, v. 55, n. 1, p. 23-28, ene./jun. 2011. Disponível em:

https://www.saber.ula.ve/handle/1234 56789/33482. Acesso em: 19 dez. 2017.

SANTOS, R. L. Caracterização geoambiental e morfométrica da bacia hidrográfica do riacho AçaizalMA. 2014. 93 f. TCC (Graduação) - Curso de Geografia, Universidade Estadual do Maranhão, Imperatriz, 2014. Disponível em: 
http://files.labcartecesiuema.webnode.c om/200000433c6d46c9bf7/CARACTERIZA\%C3\%87\%C 3\%830\%20GEOAMBIENTAL $\% 20 \mathrm{E} \% 20$ MORFOM\%C3\%89TRICA....pdf. Acesso em: 11 dez. 2017.

SANTOS, R.L.; SANTOS, R.S; BARBOSA, R.S. Caracterização da bacia hidrográfica do riacho açaizal em Senador La Rocque - Brasil. Geoaraguaia, v.3, n.2, p. 159181, ago/dez. 2013. Disponível em: http://oca.ufmt.br/index.php/geoaragua iaold/article/viewArticle/453. Acesso em: 14 dez. 2017.

SCHIAVO, B. N.V.; HENTZ, A.M.K..; CORTE, A. P. D. SANQUETTA, C.R. Caracterização da fragilidade ambiental de uma bacia hidrográfica urbana no município de Santa Maria - RS. Revista

Eletrônica em Gestão, Educação e Tecnologia Ambiental, Santa Maria, v. 20, n. 1, p. 464-474, jan./abr. 2016. Disponível em:

https://periodicos.ufsm.br/index.php/re get/article/view/19981. Acesso em: 16 dez. 2017.

SCHMITT, A.; MOREIRA, C. R. Manejo e gestão de bacia hidrográfica utilizando o software gratuito Quantum-GIS. Revista Cultivando o saber, n. Edição Especial, p. 125 - 137. 2015. Disponível em: https://www.fag.edu.br/upload/revista/ cultivando o saber/566ec59f31e47.pdf. Acesso em: 15 dez. 2017.

SEBUSIANI, H. R. V.; BETTINE, S. C. Metodologia de análise do uso e ocupação do solo em micro bacia urbana. GeDR . v. 7, n. 1, p. 256-285, jan/abr. 2011. Disponível em: http://rbgdr.net/revista/index.php/rbg $\mathrm{dr} /$ article/view/366. Acesso em: $15 \mathrm{dez}$. 2017.

SILVA, A. R.; SILVA, M. F.; SANTOS, L. C. A. Caracterização morfométrica da bacia hidrográfica do rio Cacau-MA. Revista Percurso, Maringá, v. 6, n. 2, p.141-153, ago, 2014. Disponível em: http://eduem.uem.br/laboratorio/ojs/in dex.php/Percurso/article/view/24262. Acesso em: 11 dez. 2017.

SILVA, C. A.; MARQUES, C.; MAGALHÃESJR, A.; Caracterização morfométrica da bacia do rio Maquiné - Borda Leste do Quadrilátero Ferrífero/MG. Revista Geonorte, Edição Especial 4, v.10, n.1, p.217-221, out, 2014a. Disponível em: http://www.periodicos.ufam.edu.br/revi sta-geonorte/article/view/1549. Acesso em: 17 dez. 2017.

SILVA, E.R.; DELGADO, R.C.; SOUZA, L.P.; SILVA, I.S. Caracterização física em duas bacias hidrográficas do Alto Juruá, Acre.

Revista Brasileira de Engenharia Agrícola e Ambiental. v.18, n.7, p.714719, jul, 2014b. Disponível em: http://www.agriambi.com.br/revista/v1 8n07/v18n07a07.pdf. Acesso em: 16 dez. 2017.

SILVA, J. L.; TONELLO, K. C.; Morfometria da bacia hidrográfica do Ribeirão dos Pinheirinhos, Brotas - SP. Irriga, Botucatu, v. 19, n. 1, p. 103-114, jan./mar. 2014. Disponível em: http://200.145.140.50/index.php/irriga /article/view/713. Acesso em: $11 \mathrm{dez}$. 2017.

SILVA, R.M. P.; LIMA, J. R; MENDONÇA, I. F. C.. Alteração da cobertura vegetal na sub-bacia do rio Espinharas de 2000 a 2010. Revista Brasileira de Engenharia Agrícola e Ambiental , v.18, n.2, p.202-209, fev, 2014c. Disponível em: http://www.agriambi.com.br/revista/v1 8n02/v18n02a11.pdf. Acesso em: 11 dez. 2017.

SOUZA, J. O. P.; ALMEIDAJ. D. M.; CORREA, A. C. B. Caracterização e 
espacialização da precipitação em bacia hidrográfica com relevo complexo: sertão central pernambucano - bacia do Riacho do Saco. Revista de Geografia (UFPE). v. 32, n. 2, 2015. Disponível em: https://www.researchgate.net/profile/I onas Otaviano De Souza/publication/30 6092206 CARACTERIZACAO E ESPACIA LIZACAO DA PRECIPITACAO EM BACIA HIDROGRAFICA COM RELEVO COMPL EXO SERTAO CENTRAL PERNAMBUCA NO -

BACIA DO RIACHO DO SACO WORK A ND RAINFALL CHARACTERIZATION AN D SPATIALIZATION IN/links/57afb9cf0 8aeb2cf17c2989f/CARACTERIZACAO-EESPACIALIZACAO-DA-PRECIPITACAO-

EM-BACIA-HIDROGRAFICA-COMRELEVO-COMPLEXO-SERTAO-CENTRALPERNAMBUCANO-BACIA-DO-RIACHODO-SACO-WORK-AND-RAINFALLCHARACTERIZATION-ANDSPATIALIZATION-IN.pdf. Acesso em: 11 dez. 2017.

TRENTIN, R.; DE SOUZA ROBAINA, L. E.; DA SILVEIRA, C. T. Compartimentação geomorfométrica da bacia hidrográfica do rio ITÚ/RS geomorphometric compartmentation of river basin ITU/RS. Revista Brasileira de

Geomorfologia, v. 16, n. 2, 2015. Disponível em:

https://www.researchgate.net/profile/R omario Trentin/publication/290622255 COMPARTIMENTACAO GEOMORFOME TRICA DA BACIA HIDROGRAFICA DO R I0 ITURS/links/59c294310f7e9b21a82a 9c80/COMPARTIMENTACAOGEOMORFOMETRICA-DA-BACIAHIDROGRAFICA-DO-RIO-ITU-RS.pdf. Acesso em: 11 dez. 2017.

VEIGA, A. M.; DOS SANTOS, C. C. P.; CARDOSO, M. R. D.; LINO, N.

C. Caracterização hidromorfológica da bacia do rio Meia Ponte. Caminhos de Geografia, v. 14, n. 46, 2013. Disponível em: http://www.seer.ufu.br/index.php/cami nhosdegeografia/article/view/21013. Acesso em: 11 dez. 2017.

VILLELA, S.M.; MATTOS, A. Hidrologia aplicada. São Paulo: McGRAWHill do Brasil, 1975. 245p. 